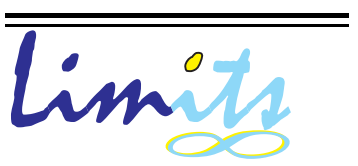

J. Math. and Its Appl.

ISSN : $1829-605 \mathrm{X}$

Vol. 1, No. 2, Nov. 2004, 29-39

\title{
Aplikasi Transformasi Wavelet Pada Prapengolahan Sinyal Suara
}

\author{
Nurul Hidayat \\ Jurusan Matematika FMIPA ITS, Surabaya \\ email: nurulhdy@yahoo.com
}

\section{Ringkasan}

Salah satu faktor penting didalam membangun sebuah sistem pengidentifikasi suara adalah proses prapengolahan data primer dari sinyal suara yang akan diidentifikasi. Prapengolahan sinyal diperlukan untuk mendapatkan besaran yang mengandung informasi berupa pola atau karakteristik dari sinyal itu. Metode estimasi trispektrum merupakan salah satu metode yang bisa digunakan untuk mendapatkan karakteristik suara berdasarkan analisis spektrum orde 4 (quadruple correlation) dari magnitudo dan fase sinyal suara.

Pola atau karakteristik dari sinyal akan berubah dari aslinya jika sinyal suara tersebut mengandung noise. Semakin besar noise yang dikandungnya, semakin besar pula perubahan polanya. Oleh sebab itu, diperlukan suatu metode untuk menghilangkan kandungan noise yang terdapat pada sinyal sebelum sinyal tersebut diestimasi, agar pola sinyal aslinya bisa didapatkan kembali. Pada makalah ini dibahas aplikasi transformasi wavelet untuk proses denoising (penghilangan noise), sebagai bagian dari prapengolahan data primer.

Dari ujicoba terhadap sinyal suara kata "atas", "bawah", "kanan", "kiri", "maju", "mundur", "naik", "turun", "buka", "tutup" yang direkam menggunakan Personal Computer yang dilengkapi dengan Microphone dan perangkat lunak Goldwave, kemudian masing-masing ditambahi noise Gaussian dengan SNR (Signal to Noise Ratio) 1, 2, 4, dan 7 dB, aplikasi transformasi wavelet untuk proses denoising berhasil dengan baik, walaupun secara kuantitatif tidak bisa menghilangkan noise 100\%, akan tetapi se- 
cara kualitatif menghasilkan sinyal suara yang (hampir) sama dengan sinyal aslinya.

Kata kunci: sinyal suara, estimasi trispektrum, magnitudo, fase, noise Gaussian, transformasi wavelet.

\section{Pendahuluan}

Perkembangan teknologi informasi dewasa ini mengalami kemajuan yang sangat pesat, khususnya yang berkaitan dengan alat-alat elektronis yang serba otomatis, praktis pemakaiannya, nyaman, memiliki portabilitas tinggi, dan harganya terjangkau untuk kalangan menengah atas. Berbagai produk teknologi informasi yang dipasarkan saat ini semakin memanjakan konsumen, misalnya pesawat telepon yang memiliki memory, pintu elektronis, mesin-mesin sensor, robot, dan lainlain.

Salah satu bagian penting untuk dapat memberikan kontribusi terhadap perkembangan teknologi informasi adalah dengan menciptakan atau mengembangkan suatu sistem pengidentifikasi. Cabang matematika terapan yang sangat berperan untuk keperluan identifikasi individu adalah biometrika. Bidang garap terpenting biometrika adalah mengidentifikasi individu melalui ciri/sifat biologis yang khusus, misalnya untuk pengenalan wajah, selaput retina, sidik jari, dan suara seseorang.

Umumnya, pengembangan sistem pengidentifikasi dipengaruhi oleh tiga status pengolahan datanya, yakni status pengolahan data primer (prapengolahan data), pengolahan data untuk mengekstraksi ciri (kuantisasi data), dan pengklasifikasi data. Metode estimasi trispektrum merupakan salah satu cara yang bisa digunakan untuk prapengolahan data didalam mendapatkan besaran magnitudo dan fase sinyal. Melalui data magnitudo dan fase inilah ciri atau pola sinyal dapat diperoleh. Hanya saja, ciri dari sinyal ini akan berubah jika sinyal tersebut mengandung noise. Pada gilirannya, ini akan berakibat pada penurunan tingkat penegenalan sistem [1]. Oleh sebab itu, diperlukan suatu metode untuk menghilangkan kandungan noise yang terdapat pada sinyal sebelum sinyal tersebut diestimasi, agar pola sinyal aslinya bisa didapatkan kembali.

Pada makalah ini akan dibahas aplikasi transformasi wavelet untuk proses denoising (penghilangan noise), sebagai bagian dari prapengolahan data primer. Penekanan bahasan terletak pada aspek praktis dari aplikasi transformasi wavelet, bukan pada aspek teoritis. 


\title{
2. Sinyal Suara
}

Sinyal suara ucapan merupakan sinyal yang deterministik karena meiliki durasi waktu yang berhingga; artinya nilai-nilai sinyal di luar kisaran durasi sinyal adalah nol. Sinyal suara ucapan juga merupakan sinyal transien (sinyal energi) karena total energi yang dikandungnya besarnya berhingga. Nilai-nilai sinyal suara ucapan adalah riil, aperiodik, dan memiliki rerata nol [2].

Definisi 2.1 Sinyal stasioner adalah sinyal yang nilainya di suatu titik waktu tertentu bersifat tetap.

Definisi 2.2 Sinyal ergodik adalah sinyal yang memiliki sifat bahwa nilai rata-rata dari beberapa sinyal sama dengan nilai dari satu sinyal.

Sinyal suara ucapan diasumsikan merupakan sinyal yang stasioner dan ergodik. Asumsi ini diperlukan agar metode estimasi trispektrum dapat diterapkan pada sinyal suara ucapan.

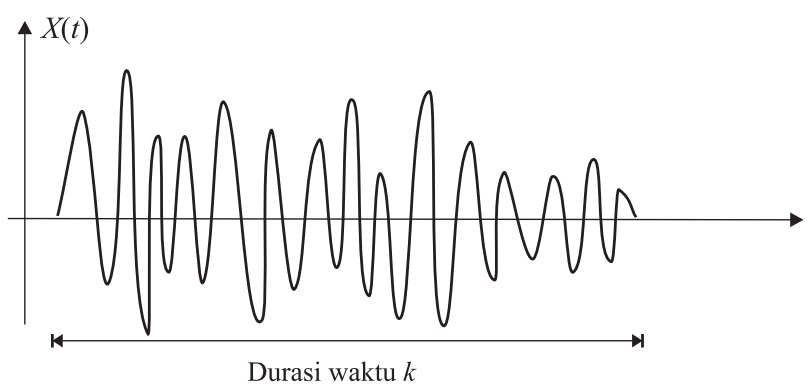

Gambar 1: Sinyal $X(t)$ dengan durasi waktu $k$

\section{Desain dan Implementasi Transformasi Wavelet}

Desain algoritma untuk proses denoising adalah sebagai berikut:

\author{
ALGORITMA DENOISING \\ input: $\mathrm{x}$ (vektor) \\ output: xden (vektor)
}




\section{Deskripsi}

Tahapan denoising signal 1-d adalah sebagai berikut:

1. Transformasi wavelet diterapkan pada signal $\mathbf{x}$ sampai level ke-5, dihasilkan vektor xc (berisi koefisien-koefisien transformasi) dan xl (berisi panjang koefisien masing-masing level transformasi).

2. Membangun vektor skala sk berdasarkan koefisien- koefisien transformasi ke-1.

3. Menentukan nilai threshold thr menggunakan metode SURE.

4. Penskalaan thr berdasarkan vektor skala sk.

5. Thresholding vektor xc menggunakan threshold thr dan informasi xl, dihasilkan vektor $\mathbf{x c d}$.

6. Rekonstruksi signal xden dari vektor $\mathbf{x c d}$ dan $\mathbf{x l}$

\section{Pseudocode}

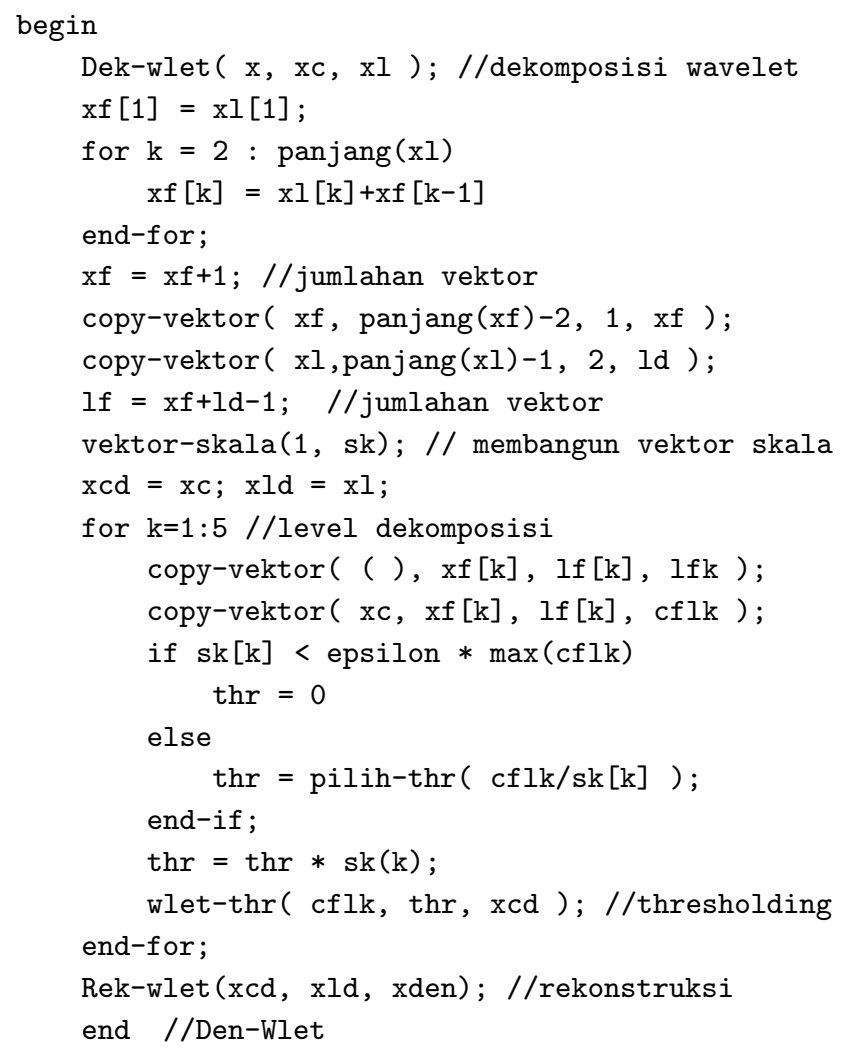


Selanjutnya, algoritma diatas diimplementasikan ke dalam sebuah program Matlab. Didalam program ini juga disertai proses penambahan noise Gaussian (noising) dengan SNR (Signal to Noise Ratio) 1, 2, 4, dan 7 dB. Selengkapnya, implementasi dari algoritma transformasi wavelet adalah sebagai berikut:

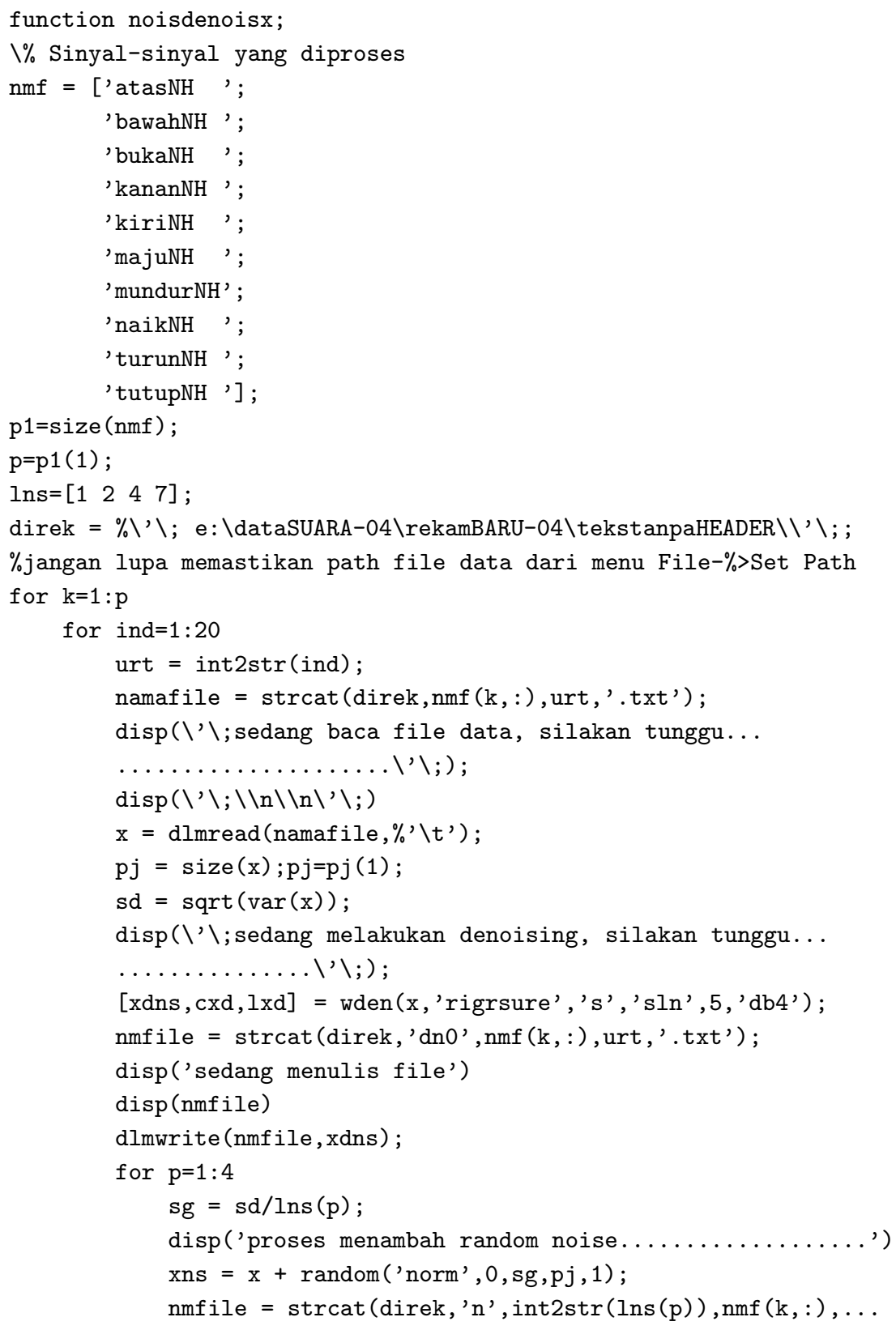




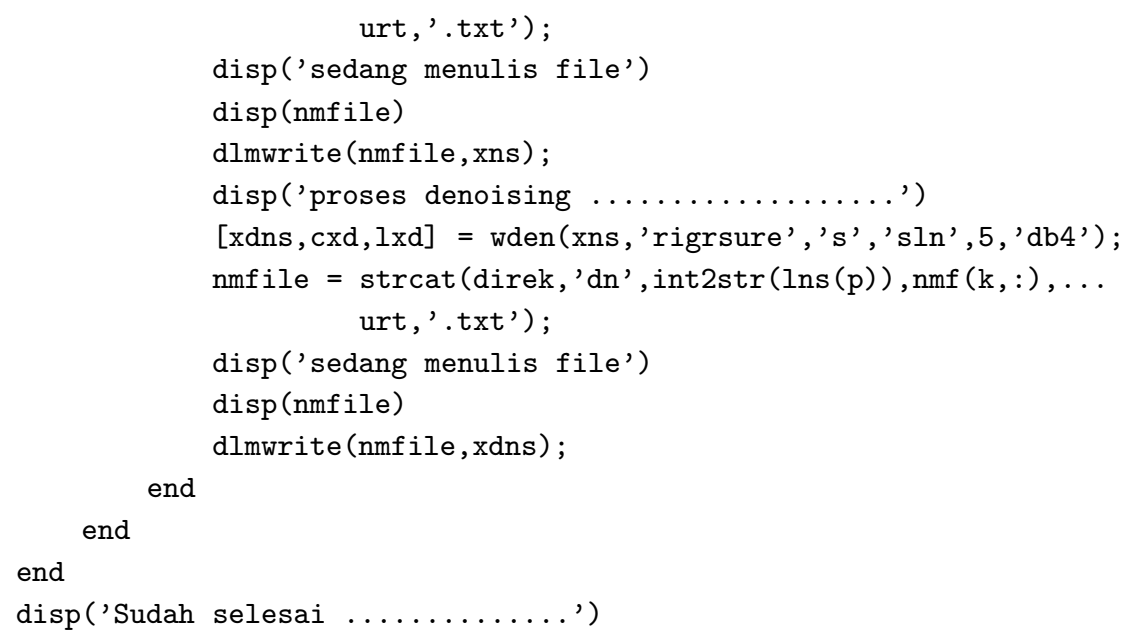

\section{Hasil Ujicoba dan Pembahasan}

\subsection{Hasil Ujicoba}

Berikut ini hasil ujicoba aplikasi transformasi wavelet untuk proses noising dan denoising terhadap sinyal suara kata "maju" yang diucapkan oleh Nurul Hidayat dan direkam melalui sebuah komputer personal yang dilengkapi dengan microphone dan perangkat lunak Goldwave pada frekwensi $11025 \mathrm{~Hz}$.

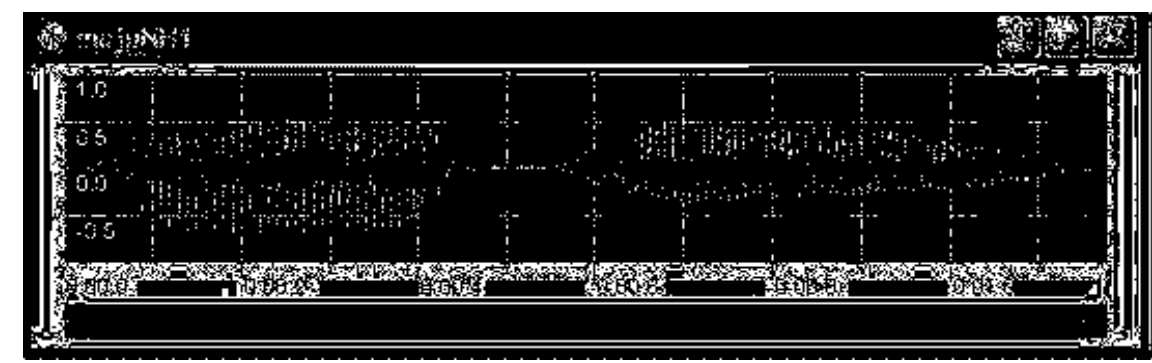

Gambar 2: Sinyal tanpa noise atau sinyal asal

Gambar-gambar di atas menunjukkan perbandingan kualitatif antara sinyal asal, bernoise dan setelah di-denoise. 


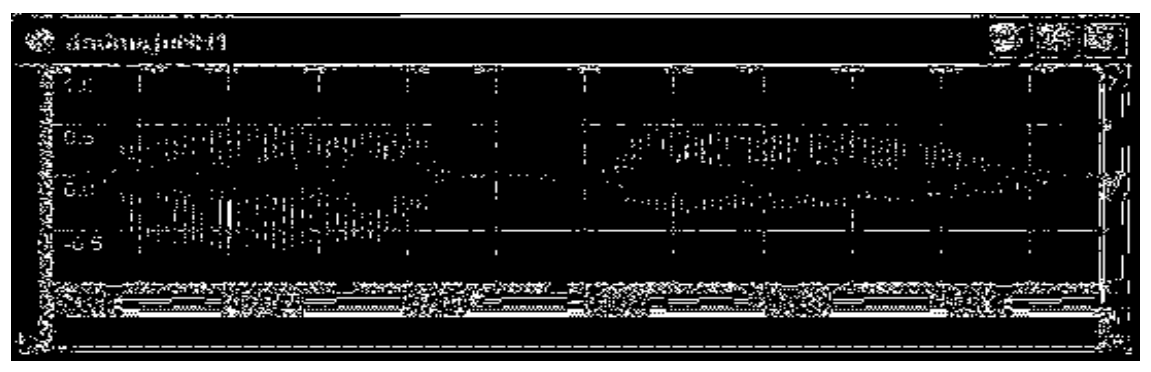

Gambar 3: Sinyal tanpa noise di-denoise

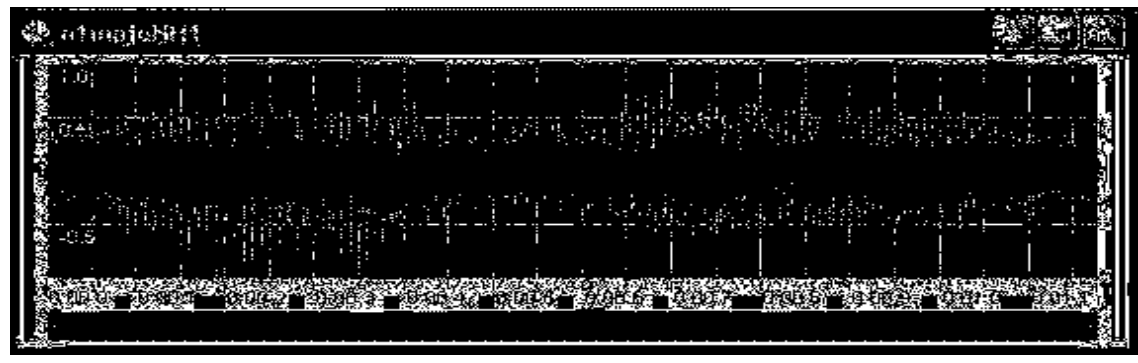

Gambar 4: Sinyal asal ditambahi noise dengan SNR $=1 \mathrm{~dB}$

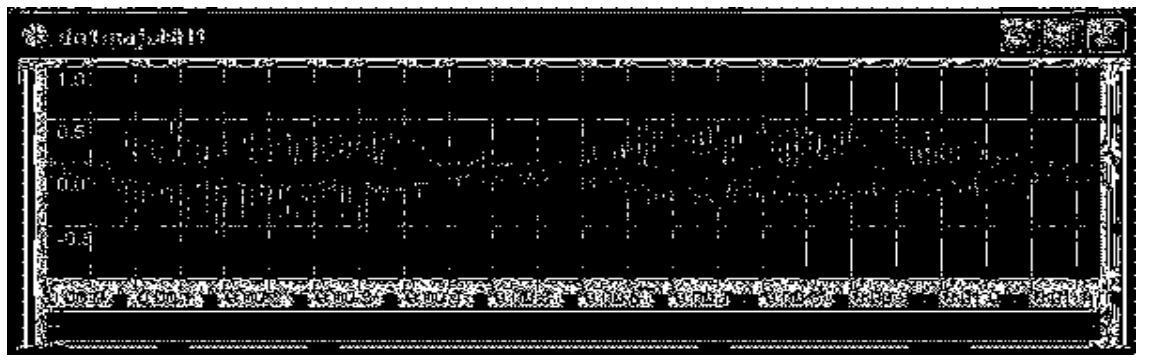

Gambar 5: Sinyal dengan noise SNR $=1 \mathrm{~dB}$ yang sudah didenoise

\subsection{Pembahasan}

Dari Gambar 2-5 di atas tampak bahwa hasil rekonstruksi sinyal bernoise dengan $\mathrm{SNR}=1$ yang kemudian didenoise, hasilnya sudah mendekati sinyal aslinya (sinyal asal). Sedangkan secara kuantitatif, sebagaimana data pada Tabel 1, tampak dengan jelas bahwa masih ada selisih (perbedaan) yang cukup signifikan antara sinyal asal dan hasil denoising untuk sinyal bernoise dengan $\mathrm{SNR}=1$. Hal ini dapat dijelaskan sebagai berikut:

Denoising berbasis wavelet untuk suatu signal 1-dimensi pada dasarnya adalah 
Tabel 1: Perbandingan kuantitatif antara sinyal asal, sinyal bernoise, dan Setelah didenoise

\begin{tabular}{|l|l|l|l|}
\hline Sinyal asal & $\begin{array}{l}\text { Sinyal asal di- } \\
\text { tambahi noise } \\
\text { SNR=1 }\end{array}$ & $\begin{array}{l}\text { Sinyal asal di- } \\
\text { denoise }\end{array}$ & $\begin{array}{l}\text { Sinyal dengan } \\
\text { noise SNR=1, } \\
\text { didenoise }\end{array}$ \\
\hline 0.01773 & 0.096309 & 0.017746 & -0.017112 \\
0.01819 & 0.16678 & 0.017565 & -0.029594 \\
0.01822 & -0.12668 & 0.017362 & -0.037755 \\
0.01855 & -0.085722 & 0.017137 & -0.039927 \\
0.01822 & 0.055832 & 0.016879 & -0.044058 \\
0.01788 & -0.22592 & 0.016589 & -0.047759 \\
0.01648 & 0.014077 & 0.016117 & -0.051117 \\
0.01465 & 0.036382 & 0.015444 & -0.054932 \\
0.01443 & -0.18472 & 0.014641 & -0.057247 \\
0.01279 & -0.062374 & 0.013661 & -0.058232 \\
0.01221 & -0.22544 & 0.013098 & -0.059077 \\
0.01334 & -0.052362 & 0.013006 & -0.059488 \\
0.01205 & -0.018323 & 0.013062 & -0.058978 \\
0.01306 & 0.062929 & 0.013429 & -0.057672 \\
0.01331 & -0.25558 & 0.013571 & -0.056722 \\
0.01199 & -0.069924 & 0.013437 & -0.056169 \\
0.01370 & -0.078081 & 0.013428 & -0.055492 \\
0.01321 & -0.087471 & 0.013411 & -0.054989 \\
0.01352 & 0.18100 & 0.013345 & -0.053659 \\
0.01453 & -0.12314 & 0.013260 & -0.051424 \\
\hline
\end{tabular}

proses thresholding pada koefisien-koefisien hasil transformasi wavelet pada signal tersebut. Dengan demikian penentuan nilai threshold merupakan hal penting yang harus dicermati. Beberapa hal yang perlu diperhatikan berkaitan dengan proses ini adalah:

- Pemilihan Filter. Filter wavelet berpengaruh selama proses denoising, khususnya berkaitan dengan panjang filter. Akan tetapi, panjang filter wavelet hanya berhingga, bahkan sangat pendek, sehingga tidak ada masalah dengan panjang filter. Sedangkan untuk hasil transformasinya, selain filter wavelet Haar (filter Daubechies dengan panjang 2), kebanyakan filter dengan moment lebih tinggi memberikan hasil yang hampir sama. Pada penelitian ini digunakan filter Coifman dengan panjang 12 .

- Panjang Sampel. Panjang sampel akan berpengaruh, khususnya untuk thresh- 
olding yang menggunakan penskalaan sesuai level transformasi. Berkaitan dengan masalah ini, panjang (sampel) signal "disesuaikan" dengan filter yang dipilih sehingga proses konvolusinya berjalan baik.

- Signal yang dihadapi diasumsikan berbentuk $y=x+n$, dengan $y$ signal inputan yang membawa noise $n$, sehingga denoising bermaksud untuk mendapatkan signal $x$ yang bebas noise. Dalam penelitian ini diasumsikan $n$ berdistribusi normal acak bebas dengan mean nol, $n \sim \mathcal{N}\left(0, \sigma^{2}\right)$. Pada kenyataan praktis, nilai ini tidak diketahui dan harus diduga (diestimasi).

Uji secara numerik dilakukan untuk menentukan thresholding yang paling sesuai, berdasarkan:

(a) Jenis filter. Dalam hal ini akan dibandingkan hasil numerik untuk pemakaian filter Haar, Daubechies (daub3, daub4, dan daub8), Coiflets (coif4 dan coif5),

(b) Metode penentuan threshold. Thresholding yang dipilih adalah softthresholding yang sesuai untuk signal yang diporoses, yakni signal suara manusia. Sedangkan pemilihan nilai threshold yang dibandingkan adalah metode SURE (Stein's Unbiased Risk Estimator), Heuristic SURE, metode threshold global (metode Donoho), dan Minimax.

(c) Metode pensakalaan. Penskalaan yang dilakukan untuk menentukan nilai threshold, adalah: tanpa penskalaan (s1), penskalaan berdasarkan koefisien dekomposisi level satu (s2), dan penskalaan berdasarkan koefisien masingmasing level dekomposisi.

(d) Transformasi wavelet diterapkan untuk level 2, 3, dan 5 .

(e) Nilai MSE (mean square error) digunakan untuk membandingkan hasil-hasil yang diperoleh dari masing-masing uji. Hasil terbaik didasarkan atas MSE terkecil.

Sedangkan signal uji yang digunakan adalah lima signal suara yang tersimpan dalam file format text: kanan1.txt, kanan2.txt, kanan3.txt, kanan4.txt, kanan5.txt.

Berdasarkan hasil perhitungan numerik yang dilakukan, dapat dicatat beberapa hal berikut ini:

- Pemilihan filter tidak berpengaruh, dalam arti tidak terdapat perbedaan yang signifikan pada hasil denoising antara penggunaan satu filter dengan filter yang lain.

- Metode estimasi noise yang memberikan hasil terbaik adalah metode SURE. 
- Hasil denoising terbaik diperoleh pada transformasi level 5.

- Nilai threshold yang ditentukan dengan penskalaan berdasarkan koefisien dekomposisi level 1 menunjukkan nilai terbaik.

Dengan demikian, selajutnya proses denoising dilakukan dengan:

- soft-thresholding

- filter Coiflet 12

- penskalaan berdasarkan koefisien transformasi level 1.

- transformasi dilakukan sampai level 5.

- metode estimasi SURE

Penerapan cara denoising yang dipilih di atas masih memberikan hasil yang belum maksimal, dalam arti hasil denoising untuk beberapa signal uji, khususnya yang (diketahui) mempunyai tingkat noise tinggi, masih membawa noise yang "terdengar" meskipun nilai MSE yang dihasilkan sudah minimal. Hal ini dapat dijelaskan sebagai berikut:

- Signal (input) yang digunakan dalam proses denoising dianggap ber-noise, dengan hanya diketahui (diasumsikan) noise-nya berdistribusi normal acak dengan mean nol, tanpa informasi lain.

- Dalam proses thresholding dipilih nilai threshold secara otomatis (menggunakan metode SURE dengan penskalaan berdasarkan koefisien transformasi level 1, sehingga parameter lain yang terbawa oleh noise tidak diperhitungkan.

- Penentuan nilai threshold merupakan permasalahan yang sulit dan ill-defined, sebab noise itu sendiri ill-defined yakni tidak dapat terdeteksi dengan jelas, kecuali hanya dapat dirasakan atau didengarkan (untuk signal suara).

- Kesulitan dalam proses denoising di atas sebenarnya dapat diatasi dengan menetapkan nilai threshold secara manual (trial and error), yakni dengan cara mengubah-ubah nilai threshold dan menerapkannya pada proses thresholding hingga didapatkan hasil signal yang diinginkan. Akan tetapi, cara manual ini tentu sangat mahal dan tidak mungkin diterapkan pada proses denoising yang merupakan bagian dari proses lain yang berlangsung berulang-ulang dan secara otomatis.

\section{Kesimpulan}

Dari ujicoba yang dilakukan terhadap sinyal suara kata "atas", "bawah", "kanan", "kiri", "maju", "mundur", "naik", "turun", "buka", "tutup", aplikasi transformasi 
wavelet secara implementatif berhasil dilakukan. Proses denoising menggunakan transformasi wavelet terhadap sinyal yang sudah ditambahi noise Gaussian dengan $\mathrm{SNR}=7,4,2,1 \mathrm{~dB}$ berhasil menghilangkan noise walaupun tidak bisa $100 \%$, terutama untuk sinyal dengan tambahan noise Gaussian sebesar SNR=1.

\section{Pustaka}

[1] Fanany, Mohamad I. (1998), Bispectrum Pattern Analysis and Quantization to Speaker Identification, Thesis, Prog. Studi Il Komputer UI.

[2] Chui, Charles K., (1997), "Wavelets: A Mathematical Tool for Signal Processing", SIAM, Philadelphia.

[3] Daubechies, Ingrid, (1992), "Ten Lectures on Wavelets", Society for Industrial and Applied Mathematics, Philadelphia.

[4] Mendel, Jerry M. (March 1991), "Tutorial on Higher Order Statistics (Spectra)", in Signal Processing and System Theory: Theoritical Results and Some Applications, Proceedings of The IEEE Vol 79 No. 3.

[5] Nikias, Chrysostomos L. (July 1987), "Bispectrum Estimation : A Digital Signal Processing Framework", Proc. of The IEEE Vol. 75 No. 7.

[6] Nikias, Chrysostomos L, and Petropuou, Athina P. (1993), "Higher-Order Spectra Analysis : A Nonlinier Signal Processing Framework", Prentice-Hall Inc., International Editions.

[7] Owens, F.J. (1993), "Signal Processing of Speech", The Macmillan Press, Ltd.

[8] Tou, Julius T., and Gonzales, Rafael C. (1974), "Pattern Recognition Principles", Addison-Wesley Publishing Company.

[9] noname. (Sept 1997), "Speaker Recognition: A Tutorial", Proceeding of the IEEE, Vol. 85, No.9.

[10] Hadi, Rahman, "Implementasi Transformasi Wavelet Diskrit Ortonormal untuk Penghalusan Data", Skripsi, 2002. 